\title{
The Effect of Gender on Algebra Achievement: The Meta-Analysis of Trends in International Mathematics and Science Study (TIMSS)
}

\author{
Ş. Koza Çiftçi ${ }^{\mathrm{a}}$ and Pınar Yıldız
}

aAkdeniz University, Faculty of Education, Antalya/Turkey (ORCID: 0000-0002-4568-5635)
${ }^{\mathrm{b} C}$ Canakkale Onsekiz Mart University, Çanakkale/Turkey (ORCID: 0000-0002-6729-7721)

Article History: Received: 21 May 2019; Accepted: 28 August 2019; Published online: 14 November 2019

Abstract: In this meta-analysis study; the effect of gender on algebra achievement was tested in the context of TIMSS. The study was carried out in two stages: $(i)$ finding out the average effect size of gender on algebra achievement, and (ii) determining the moderators that may affect the average effect size. TIMSS 1995, 1999, 2003, 2007, 2011 and 2015 were combined and a sample of 1.202 .847 people was obtained. In the study, the average effect size was calculated using the differences between means (Cohen $d$ ) based on the random effect model, whereas the significance of the moderator variables was calculated using $Q$ statistic. The results of the study showed that gender had a low effect on achievement. In addition, the national culture, and the year of the study variables play moderator role regarding the effect of gender on achievement.

Keywords: Gender, algebra, algebra achievement, TIMSS, national culture, Human Development Index

DOI: $10.16949 /$ turkbilmat.568545

\section{Introduction}

Algebra is one of the five learning areas (numbers and operations, algebra, geometry and measurement, data processing, probability) covered in the secondary school mathematics curriculum. Algebra serves as a bridge between the other learning areas of mathematics. It is an important building block that prepares students for mathematical thinking in all areas of mathematics and in daily life (Van de Walle, Karp \& Bay-Willams, 2014). Basically, algebra is defined as generalized arithmetic or problem-solving tool (Booth, 1988; Kieran, 1992). As it has different functions, it is defined as a language and thinking tool beyond the calculation with symbols (Booth, 1988; Dede \& Argün, 2003; Vance, 1988; Kieran, 1992).

Although algebra topics are started at the secondary school level, they are included in the education programs from kindergarten to university as a thinking tool. Algebraic thinking, which is a subfield of mathematical thinking, forms the basis of other mathematics topics. Knowledge and skills in arithmetic require the use of algebraic thinking processes. For this reason, students structure their algebra-related learning by associating with their learning in arithmetic (Akkan, Baki \& Çakıroğlu, 2012; Kaput, 1998; Kieran, 1992). Studies show that many students have difficulty in understanding basic concepts of algebra and to link these concepts to pre-algebraic concepts that they developed in elementary school. Therefore, the targeted success cannot be achieved (Booth, 1988; Carraher \&

Correspondance: Ş. Koza Çiftçi ID email: kozaciftci@gmail.com

Citation information: Çiftçi, Ş. K. \& Yıldız, P. (2019). The effect of gender on algebra achievement: The meta-analysis of trends in international mathematics and science study (TIMSS). Turkish Journal of Computer and Mathematics Education, 10(3), 617627. 
Schliemann, 2007; Christou, Vosniadou \& Vamvakoussi, 2007; Dede \& Argün, 2003; Herscovics \& Linchevski, 1994; Kieran, 1992; MacGregor \& Stacey, 1997; Rosnick, 1981; Yıldız, Çiftçi, Şengil-Akar \& Sezer, 2015).

Research shows that students' algebra achievement is associated with the content of the course (Booth, 1988; Kieran, 1992; Kuchemann; 1978; Usiskin, 1999), instruction (Asquith, Stephens, Knuth \& Alibali, 2007; Caswell, 2009; Tirosh, Even \& Robinson, 1998) and students' characteristics (Else-Quest, Hyde \& Linn, 2010; McCoy, 2005). Within the scope of algebra, the basis of learning for the achievement of the students is built on the concepts of variable and equality. The understanding of these concepts is seen as the basis for the instruction of algebra and algebra topics (variable, algebraic expression, equality and equation) in the switch from arithmetic to algebra. However, the difference in the use of letter symbols in arithmetic and algebra causes students to have difficulty in understanding the concepts of variable, algebraic expression and equation (Booth, 1988; Kieran, 1981, Kuchemann, 1978, MacGregor \& Stacey, 1997; Usiskin, 1999). In the teaching of basic algebra concepts, it is necessary to use the demonstrations that students can relate to their arithmetic learning (pre-algebraic concepts). At this point, the most important task falls to the teachers. Teachers' knowledge about the subject they teach will be the most important factor affecting student achievement (Fennema, Sowder \& Carpenter, 1999; Shulman, 1986, 1987). Research shows that teachers' knowledge of algebra is not adequate (Attorps, 2003; Black, 2007; Li, 2007; Stephens, 2006, 2008; Stump \& Bishop, 2002).

Another factor affecting algebra achievement is the personal and social characteristics of the students (gender, ethnicity, socio-economic status, etc.) (McCoy, 2005). Student characteristics became the subject of studies that examine students' mathematics achievement in recent years. Among them, gender difference is one of the important dimensions whose association with mathematics achievement was examined. In the metaanalysis study of Hyde, Fennema, and Lamon (1990) reviewing 100 studies on mathematics achievement and gender difference between 1963-1988, the average effect sizes based on general population samples showed that female students were negligibly more successful than male students. Meta-analysis results show that there is very little gender difference in mathematics achievement and this difference closes over the years. The results of further analysis obtained from the research show that there is no gender difference in primary and secondary school in problem solving, but there is a difference in favor of male students in high school. Spelke (2005) also stated in his research that male students' mathematics achievement increased more rapidly than female students after 12-13 years of age and this situation created a gender difference for mathematics achievement in high school. Hyde and Mertz (2009) stated that this difference was related to the low attendance of female students on advanced mathematics courses in high school. He stated that this situation changed in the 21 st century and that female students have taken calculus lesson as much as male students. 
Regarding the literature, it is seen that the effect of gender on mathematics achievement is mostly examined within the scope of general mathematics subjects (Hyde et al., 1990; Fennema \& Sherman, 1977; Hyde \& Mertz, 2009; Kenney-Benson, Pomerants, Ryan \& Patrick, 2006; Penner \& Paret, 2008; Spelke, 2005). There are a few researches that have investigated the effect of gender on mathematics achievement within the context of algebra learning (Dugdale, DeKoven \& Ju, 1998; McCoy, 2005). In addition, these studies are often limited to data from small samples and non-standardized achievement tests. In this study, which is based on this limitation, it is aimed to analyze the results of TIMSS results within the scope of algebra learning area. Trends in International Mathematics and Science Study (TIMSS), is a four-year survey research conducted by International Association for the Evaluation of Educational Achievement (IEA). TIMSS evaluates the mathematics achievement of 8th grade students by using the achievement test which includes questions on numbers, algebra, geometry, data and probability learning areas. Algebra learning area includes questions about patterns, algebraic expressions and equations topics (Büyüköztürk, Çakan, Tan \& Atar, 2014; Şişman, Acat, Aypay \& Karadağ, 2011).

Within TIMSS, the relationship between gender and algebra is investigated as a dimension. In this context, this study aimed to analyze the results of the TIMSS, addressing (i) finding out the average effect size of the gender on algebra achievement, and (ii) the determination of the moderators that may affect the average effect size. For this purpose, the following hypotheses were tested in the research:

$\boldsymbol{H}_{1}$ Gender affects student's algebra achievement.

$\boldsymbol{H}_{2}$ The culture of the country in which the research is conducted (vertical-collective $\&$ horizontal-individualist culture) is a moderator regarding the effect of gender on the algebra achievement.

$\boldsymbol{H}_{3}$ Human Development Index is a moderator regarding the effect of gender on the algebra achievement.

$\boldsymbol{H}_{4}$ The year of the research is a moderator regarding the effect of gender on the algebra achievement.

\section{Method}

\subsection{Study Sample and Selection Criteria}

Although there are many individual studies on the effect of gender on academic achievement in the literature, there are few studies conducted in the context of national culture. In this study, which is based on overcoming this deficiency, the meta-analysis of the TIMSS, in which standardized achievement tests are used, was performed. In the study, 238 independent research results of 69 countries in six TIMSS 1995, 1999, 2003, 2007, 2011 and 2015 were combined and a sample group of 1.202 .847 people was obtained. 


\subsection{Coding Process}

Coding is a data extracting process performed to extract clear data that is more convenient to work with from the complex data of the studies (Çoğaltay \& Karadağ, 2015). In the study, a coding form was developed before starting statistical analysis and the coding was performed in accordance with this form. The main objective here is to develop a special coding system that is generic enough to see all studies and so special that no feature of a single study would be skipped. It was composed of the following components;

- Sample information [Year of study, country, course, etc.]

- Quantitative figures [Sample size, average achievement, standard deviation, etc.]

\subsection{Effect Size Analysis}

The average effect size is a standard measure used in meta-analysis to determine the strength and direction of the relationship (Borenstein, Hedges, Higgins \& Rothstein, 2009). In the study, Standardized Means Differences (Cohen $d$ ) were calculated for the analysis of the hypothesis. Standardized Average Effect Size is used to compare the means of independent groups, which is considered to be comparable for the studies based on each of the two variables (Hedges \& Olkin, 1985). The meta-analysis process of this study was based on random effects model. Comprehensive Meta-Analysis program was used to analyze the data.

\subsection{Moderator Variables and Moderator Analysis}

Moderator analysis is an analysis method that allows to test the direction of the differences between the sub-groups and the differences between the average effect sizes of the variables (moderators). In this study, only $Q_{b}$ values were used because the objective was to test the statistical significance of the differences between the moderators. In the study, three moderator variables which were thought to play a role in the average effect size were determined, which are $(i)$ the culture of the country in which the research is conducted, (ii) the Human Development Index, and (iii) the year in which the survey was conducted.

\section{Findings}

\subsection{Findings about Average Effect Size}

The funnel plot of the studies included in the meta-analysis, performed to determine whether there is a publication bias in the study is presented in Figure 1. As seen in Figure 1, it was found that there was no effect arising from publication bias in the studies included in the analysis. No evidence was observed for the publication bias of 238 independent results included in the meta-analysis according to the funnel plot. 


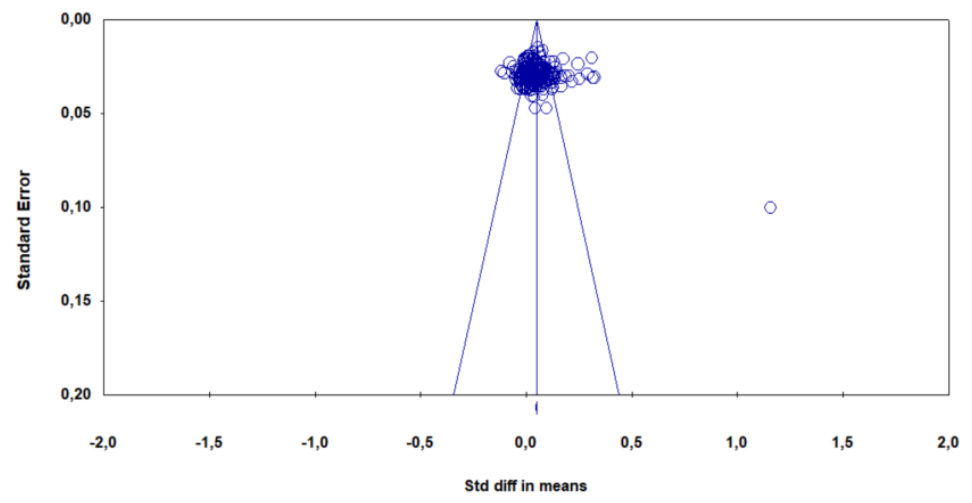

Figure 1. Funnel Plot of the effect size related to publication bias

Although there was no evidence of publication bias in the funnel plot, Trim and Fill test was performed to evaluate the amount of the effect related to publication bias in the effect size obtained as a result of meta-analysis performed according to random effects model and the results are presented in Table 1. As seen in Table 1, there is no difference between the observed effect size and the virtual effect size created according to the random effects model to correct the effect caused by the publication bias. This is the proof that there is no publication bias.

Table 1. Results of trim and fill test

\begin{tabular}{|c|c|c|c|c|c|}
\hline & \multirow{2}{*}{ Study } & \multirow{2}{*}{$\begin{array}{c}\text { Point } \\
\text { Estimation }\end{array}$} & \multicolumn{2}{|c|}{ CI (Confidence Interval) } & \multirow[b]{2}{*}{$Q$} \\
\hline & & & $\begin{array}{c}\text { Lower } \\
\text { Limit }\end{array}$ & Upper Limit & \\
\hline Observed values & & 0,048 & 0,039 & 0,057 & 1383,58 \\
\hline Corrected values & 0 & 0,048 & 0,039 & 0,057 & 1383,58 \\
\hline
\end{tabular}

\subsection{Findings Related to Average Effect Size}

The results of the meta-analysis showing the effect of students' gender on "algebra achievement" are presented in Table 2. The findings supported $H_{l}$ hypothesis suggesting that gender has an effect on students' algebra achievement. The effect of gender on the algebra achievement $(d)$ is calculated as 0,048 and it is statistically significant. This value indicates that gender has a low (Cohen, 1988) effect on algebra achievement. This finding indicates that female students are more successful than males in algebra.

Regarding the other hypothesis, the year in which the study was conducted, the national culture in which the research was conducted, and the countries' Human Development Index were supposed to be moderator regarding the effect of gender on the algebra achievement. The effect of gender on algebra achievement obtained from moderator analysis is as follows 
(in favor of females);

- It is significantly higher in horizontal-individualist cultures $(d=0.057)$ than vertical-collectivist cultures $(d=0.032)\left(\mathrm{Q}_{b}=10.4 ; \mathrm{p}<.01\right)$.

- There are significant differences according to the years of research and the highest effect belongs to 2007 [1995 $(d=0,032) ; 1999(d=0,016) ; 2003(d=0,053) ; 2007$ $(d=0,068) ; 2011(d=0,059)$ and $2015(d=0,051)]\left(\mathrm{Q}_{b}=8,65 ; p<.01\right)$.

- Human Development Index of the countries where research is conducted is not significant $\left(\mathrm{Q}_{b}=15,05 ; p<.01\right)$.

Table 2. The Effect of Gender on Students' Algebra Achievement: Meta-analysis Results

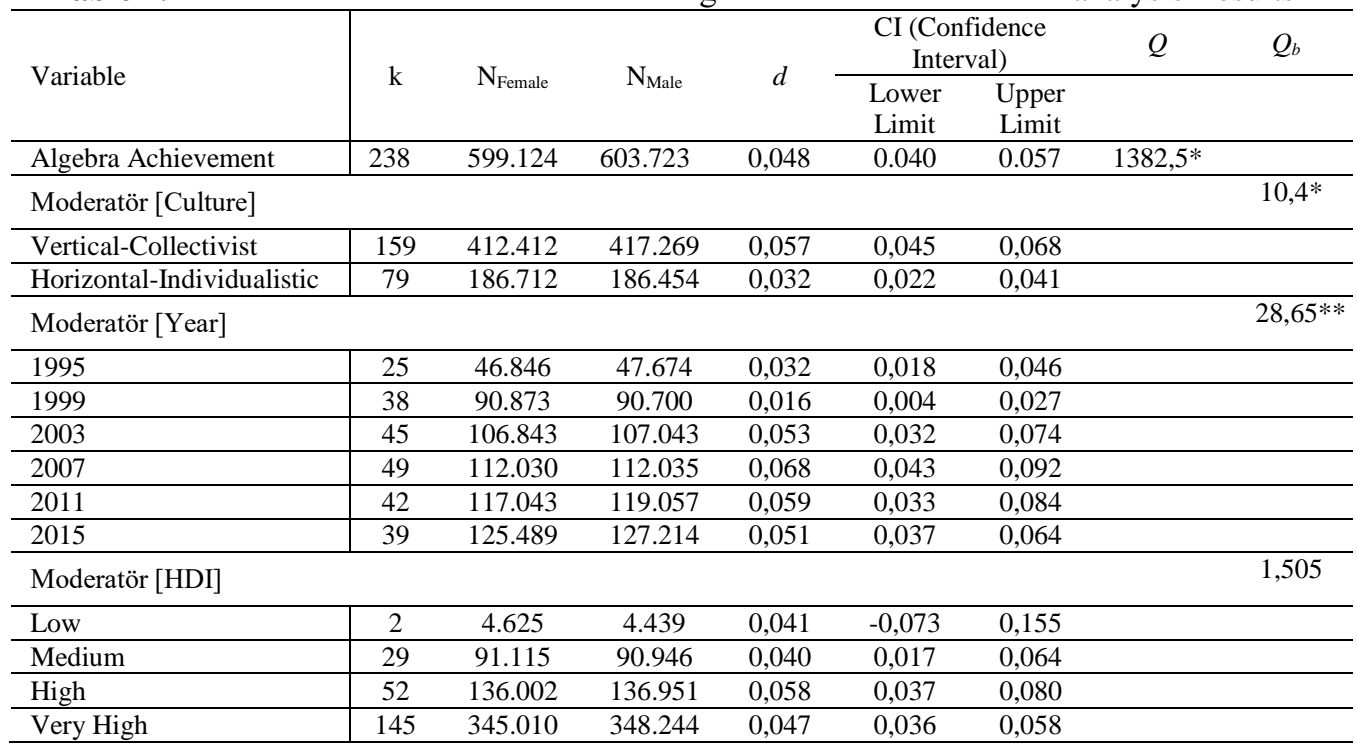

$* p<.05, * * p<.01$

Regarding the individual average effect sizes of the 69 countries included in the study, it was found that gender had a significant effect on the algebra achievement in 34 countries. In all these 34 countries, females' algebra achievements are significantly higher than males. The countries with the highest effect are Bahrain, Oman, Cyprus, Qatar and Botswana, respectively. The effect sizes according to country are presented in Table 3. 
Table 3. The Effect of Gender on Algebra Achievement according to Country

\begin{tabular}{|c|c|c|c|c|c|}
\hline Country & $d$ & Country & $d$ & Country & $d$ \\
\hline Bahrain & 0,453 & Singapore & 0,053 & New Zealand & 0,023 \\
\hline Oman & 0,258 & Saudi Arabia & 0,052 & United States & 0,016 \\
\hline Cyprus & 0,179 & Philippines & 0,052 & Italy & 0,016 \\
\hline Qatar & 0,128 & Czech Republic & 0,050 & Hong Kong & 0,015 \\
\hline Botswana & 0,126 & Iran & 0,048 & Canada & 0,014 \\
\hline Palestinian & 0,121 & Slovak Republic & 0,048 & Belgium & 0,012 \\
\hline Serbia & 0,110 & Egypt & 0,045 & South Africa & 0,009 \\
\hline Jordan & 0,100 & Kazakhstan & 0,044 & Japan & 0,009 \\
\hline Bosnia and Herzegovina & 0,098 & Russian Federation & 0,044 & Estonia & 0,007 \\
\hline Lithuania & 0,095 & Iceland & 0,044 & Netherlands & 0,006 \\
\hline Romania & 0,091 & Hungary & 0,043 & Algeria & 0,006 \\
\hline Latvia & 0,085 & Syrian Arab Republic & 0,041 & Korea & 0,004 \\
\hline Kuwait & 0,084 & Georgia & 0,040 & Ireland & 0,001 \\
\hline Armenia & 0,083 & Indonesia & 0,040 & France & 0,000 \\
\hline Malta & 0,077 & Morocco & 0,039 & Spain & 0,000 \\
\hline Slovenia & 0,075 & Ukraine & 0,037 & Switzerland & 0,000 \\
\hline Macedonia & 0,068 & Thailand & 0,036 & Australia & 0,000 \\
\hline United Arab Emirates & 0,066 & Chinese Taipei & 0,034 & Lebanon & $-0,013$ \\
\hline Turkey & 0,066 & Norway & 0,032 & Tunisia & $-0,014$ \\
\hline Finland & 0,059 & Israel & 0,030 & Chile & $-0,022$ \\
\hline Malaysia & 0,058 & UK & 0,026 & El Salvador & $-0,052$ \\
\hline Bulgaria & 0,056 & Portugal & 0,024 & Ghana & $-0,080$ \\
\hline Moldova & 0,056 & Sweden & 0,024 & Colombia & $-0,104$ \\
\hline
\end{tabular}

\section{Discussion and Conclusion}

In this meta-analysis, the effect of gender on "algebra achievement" was investigated in the context of TIMSS. The findings show that gender has a low but significant effect on students' algebra achievement. In other words, female students' "algebraic achievement scores" are higher than male students. McCoy (2005), in her study of eighth grade students, found that gender did not have an effect on students' algebra achievement. However, researches showed that in 21st century, female students prefer more the courses such as algebra and advanced mathematics after high school. As a result of this fact, the gender difference in mathematics achievement decreased compared to before 21 century (ElseQuest et al., 2010; Hyde \& Mertz, 2009) and nowadays this difference is increasing in favor 
of females (Hyde \& Mertz, 2009; Spelke, 2005). It can be said that these results, along with other studies, are an important indicator to break down the prejudices that girls fail in mathematics.

The findings of the survey show that the effect of gender on algebra achievement is higher in countries with horizontal individualist culture (e.g., such as the US) compared to the countries with vertical-collectivist culture (e.g., such as Turkey). According to this, females in horizontal-individualist culture show higher algebra achievement than males. Regarding career choices, nowadays, female students in horizontal-individualist countries makes more career planning in the areas that require using mathematics, such as physics and chemistry, after secondary school (Else-Quest et al., 2010; Hyde \& Mertz, 2009). However, female students in countries with vertical-collectivist culture remain in the shadow.

This meta-analysis study was conducted by analyzing the data of 69 countries. In 34 of these 69 countries, females' algebra achievements are higher than males. The countries with the highest impact are mostly third world countries, such as Bahrain, Oman, Cyprus, Qatar and Botswana. Research results by Else-Quest et alia (2010) also support this situation. In these countries, the most important reason for girls to achieve higher algebra success is the schooling rate of girls. This is because the schooling rates of girls are very low in the third world countries, and the girls who attend school are generally the children of families with high socio-economic level. This high difference is due to the fact that female students who are likely to show low achievement stayed out of research (out of school).

The results obtained in this research and other researches show that gender has generally a low-level effect on mathematics achievement and on algebra achievement as a subfield of mathematics. In this context, new studies investigating the effect of gender on the algebra achievement as a subfield of mathematics at different grade levels are needed. Considering the importance of algebra in mathematics achievement, it is important to ensure that gender difference is minimized in the teaching process.

\section{References}

Akkan, Y., Baki, A., \& Çakıroğlu, Ü. (2012). 5-8. sınıf öğrencilerinin aritmetikten cebire geçiş süreçlerinin problem çözme bağlamında incelenmesi. Hacettepe Üniversitesi Ĕ̈itim Fakültesi Dergisi, 43, 1-13.

Asquith, P., Stephens, A. C., Knuth, E. J., \& Alibali, M. W. (2007). Middle school mathematics teachers' knowledge of students' understanding of core algebraic concepts: Equal sign and variable. Mathematical Thinking and Learning, 9(3), 249-272.

Attorps, I. (2003). Teachers' images of the 'equation' concept. European Research in Mathematics Education, 3, 1-8. 
Black, D. J. W. (2007). The relationship of teachers' content knowledge and pedagogical content knowledge in algebra, and changes in both types of knowledge as a professional development (Unpublished doctoral dissertation). Auburn University, USA.

Booth, L. (1988). Children's difficulties in beginning algebra. In A. F. Coxford, \& A. P. Shulte (Eds.), The ideas of algebra, K-12 (pp. 20-32). Reston: VA.

Büyüköztürk, Ş., Çakan, M., Tan, Ş., \& Atar, H. Y. (2014). TIMSS 2011 ulusal matematik ve fen raporu 8. sinıflar. Ankara: Milli Eğitim Bakanlığı.

Borenstein, M., Hedges, L. V., Higgins, J. P., \& Rothstein, H. R. (2009). Introduction to meta-analysis. Chichester, West Sussex: John Wiley \& Sons.

Carraher, D. W., \& Schliemann, A. D. (2007). Early algebra and algebra reasoning. In F. Lester (Ed.), Second handbook of research on mathematics teaching and learning: A project of the National Council of Teachers of Mathematics (pp. 699-705). Greenwich, CT: Information Age Publishing.

Caswell, L. M. (2009). The algebra content knowledge of beginning teachers in California (Unpublished doctoral dissertation). Capella University, USA.

Christou, K. P., Vosniadou, S., \& Vamvakoussi, X. (2007). Students' interpretations of literal symbols in algebra. In S. Vosniadou, A Naltas, \& X. Vamvakoussi (Eds.), Reframing the conceptual change approach in learning and instruction (pp. 283-297). London: Elsevier.

Cohen, J. (1988). Statistical power analysis for the behavioral sciences. Hillsdale, NJ: Lawrence Erlbaum Associates.

Çoğaltay, N., \& Karadağ, E. (2015). Introduction to meta-analysis. In E. Karadağ (Ed.), Leadership and organizational outcomes (pp. 19-28). Switzerland: Springer.

Dede, Y., \& Argün, Z. (2003). Cebir, öğrencilere niçin zor gelmektedir? Hacettepe Üniversitesi Ĕ̈itim Fakültesi Dergisi, 24, 180-185.

Dugdale, S., DeKoven, E., \& Ju, M. K. (1998). Computer course enrollment, home computer access, and gender: Relationships to high school students' success with computer spreadsheet use for problem solving in pre-algebra. Journal of Educational Computing Research, 18(1), 49-62.

Else-Quest, N. M., Hyde, J. S., \& Linn, M. C. (2010). Cross-national patterns of gender differences in mathematics: A meta-analysis. Psychological Bulletin, 136(1), 103-127.

Fennema, E., Sowder, J., \& Carpenter, T. P. (1999). Creating classrooms that promote understanding. In E. Fennema, \& T. A. Romberg (Eds.), Mathematics classrooms that promote understanding (pp. 185-199). NJ: Lawrence Erlbaum Associates.

Fennema, E., \& Sherman J. (1977) Sex-related difference in mathematics achievement, spatial visualization and affective factors. American Educational Research Journal, 14(1), 51-71.

Hedges, L.V., \& Olkin, I. (1985). Statistical Methods for Meta-Analysis. Academic Press, New York

Herscovics, N., \& Linchevski, L. (1994). A cognitive gap between arithmetic and algebra. Educational Studies in Mathematics, 27(1), 59-78. 
Hyde, J. S., Fennema, E., \& Lamon, S. J. (1990). Gender differences in mathematics performance: A meta-analysis. Psychological Bulletin, 107(2), 139-155.

Hyde, J. S., \& Mertz, J. E. (2009). Gender, culture, and mathematics performance. Proceedings of the National Academy of Sciences, 106(22), 8801-8807.

Kaput, J. (1998, May). Transforming algebra from an engine of inequity to an engine of mathematical power by "algebrafying" the K-12 curriculum. Paper presented at the Algebra Symposium, Washington, DC.

Kenney-Benson, G. A., Pomerantz, E. M., Ryan, A. M., \& Patrick, H. (2006). Sex differences in math performance: The role of children's approach to schoolwork. Developmental Psychology, 42(1), 11-26.

Kieran, C. (1992). The learning and teaching of school algebra. In D. A. Grouws (Ed.), Handbook of research on mathematics teaching and learning (pp. 390-419). New York: Macmillan.

Kieran, C. (1981). Concepts associated with the equality symbol. Educational Studies in Mathematics, 12, 317-326.

Kuchemann, D. (1978). Children's understanding of numerical variables. Mathematics in School, 7(4), 23-26.

Li, X. (2007). An investigation of secondary school algebra teachers' mathematical knowledfe for teaching algebraic equation solving (Unpublished doctoral dissertation). The University of Texas, USA.

MacGregor, M., \& Stacey, K. (1997). Students' understanding of algebraic notation: 11-16. Educational Studies in Mathematics, 33, 1-19.

McCoy, L. P. (2005). Effect of demographic and personal variables on achievement in eighth-grade algebra. The Journal of Educational Research, 98(3), 131-135.

Penner, A. M., \& Paret, M. (2008). Gender differences in mathematics achievement: Exploring the early grades and the extremes. Social Science Research, 37(1), 239-253.

Rosnick, P. (1981). Some misconceptions concerning the concept of variable. Are you careful about defining your variables? Mathematics Teacher, 74(6), 418-420.

Shulman, L. S. (1986). Those who understand: Knowledge growth in teaching. Educational Researcher, 15(2), 4-14.

Shulman, L. S. (1987). Knowledge and teaching: Foundations of the new reform. Harvard Educational Review, 57(1), 1-21.

Spelke, E. S. (2005). Sex differences in intrinsic aptitude for mathematics and science?: A critical review. American Psychologist, 60(9), 950-958.

Stephens, A. C. (2006). Equivalence and relational thinking: Preservice elementary teachers' awareness of opportunities and misconceptions. Journal of Mathematics Teacher Education, 9, 249-278.

Stephens, A. C. (2008). What "counts" as algebra in the eyes of preservice elementary teachers? Journal of Mathematical Behavior, 27, 33-47.

Stump, S. L., \& Bishop, J. (2002). Preservice elementary and middle school teachers' conceptions of algebra revealed through the use of exemplary curriculum materials. In D. S. Mewborn, P. Sztajn, D. Y. White, H. G. Wiegel, R. L. Bryant, \& K. Nooney 
(Eds.), Proceedings of the twenty-fourth annual meeting of the international group for the psychology of mathematics education (pp. 1903-1914). Columbus, OH: ERIC.

Şişman, M., Acat, M. B., Aypay, A., \& Karadağ, E. (2011). TIMSS 2007 ulusal matematik ve fen raporu: 8. sinıflar. Ankara: Milli Eğitim Bakanlığı.

Tirosh, D., Even, R., \& Robinson, N. (1998). Simplifying algebraic expressions: Teacher awareness and teaching approaches. Educational Studies in Mathematics, 35(1), 51-64.

Usiskin, Z. (1999). Conceptions of school algebra and uses variables. In B. Moses (Ed.), Allgebraic thinking, grades K-12: Readings from NCTM's school-based journals and other publications (pp. 7-13). Reston, VA: Natinoal Council of Teachers Mathematics.

Vance, J. (1988). Number operations from an algebraic perspective. Teaching Children Mathematics, 4, 282-285.

Van de Walle, J. A., Karp, K. S., \& Bay-Williams, J. M. (2014). Elementary and middle school mathematics: Teaching developmentally. New Jersey: Pearson Education.

Yıldız, P., Çiftçi, Ş. K., Şengil-Akar, Ş. ve Sezer, E. (2015). Ortaokul 7. sınıf öğrencilerinin cebirsel ifadeleri ve değişkenleri yorumlama sürecinde yaptıkları hatalar. Hacettepe Üniversitesi Eğitim Bilimleri Enstitüsü Eğitim Araştırmaları Dergisi, 1(1), 18-31. 